\title{
Are matrix metalloproteinases and their inhibitors reliable diagnosis biomarkers and attractive therapeutic targets in endometriosis?
}

\author{
Patrick Henriet \\ Khin Su Mon \\ Etienne Marbaix \\ De Duve Institute, Université \\ catholique de Louvain, Brussels, \\ Belgium
}

This article was published in the following Dove Press journal:

Metalloproteinases In Medicine

7 December 2016

Number of times this article has been viewed

\begin{abstract}
Matrix metalloproteinases (MMPs) and tissue inhibitors of metalloproteinases (TIMPs) are expressed in the human endometrium during the menstrual cycle, in particular to induce substantial extracellular matrix breakdown underlying menstruation. Endometriosis (EM) is characterized by the presence of endometrial tissue at ectopic locations. Because EM is thought to often develop from retrograde menstruation followed by implantation of menstrual tissue fragments at ectopic sites, endometrial MMPs and TIMPs were rapidly suspected as contributors to EM development and progression, generating hope for their use as biomarkers to facilitate EM diagnosis and as potential targets for developing new therapies against EM. Here, we not only summarize a substantial literature supporting the presence of MMPs and TIMPs in eutopic and ectopic endometrium of EM patients but also highlight frequent controversies on expression changes and the difficulty in identifying systematic MMP/TIMP differential regulation associated with the disease. Moreover, by reanalyzing publicly available data from a whole genome transcriptomic study, we show that occasional and unexplained endometrial overexpression of selective MMPs regardless of the disease and phase of the menstrual cycle rather discourages the use of eutopic MMPs and TIMPs as diagnosis biomarkers. However, we also review multiple studies using rodent models that collectively provide strong support to the contribution of MMPs in EM development and progression, and therefore to further investigations aiming at targeting MMP activity, especially in light of recent advances in new MMP inhibitors.
\end{abstract}

Keywords: endometrium, endometriosis, biomarker, MMPs and TIMPs, therapy, animal model

\section{Introduction}

Endometriosis (EM) is a common and nonmalignant gynecological condition characterized by the presence of endometrial glands and stroma in ectopic locations, primarily the pelvic cavity, ovaries, and rectovaginal septum. EM affects $5 \%-10 \%$ of women of reproductive age and up to $50 \%$ of women experiencing pelvic pain and/or infertility, the two major symptoms leading to clinical presentation. Since confirmed EM diagnosis relies on surgical visualization of lesion, these numbers are probably underestimated, and so development of simple and reliable biomarkers is awaited with great anticipation.

Several theories have emerged to explain EM origin (reviewed in Burney and Giudice $^{1}$ and Vercellini et $\mathrm{al}^{2}$ papers) and can be classified into two groups depending on whether lesions derive from uterine endometrium (eg, by "retrograde menstruation" of menstrual tissue fragments through the fallopian tubes, the most common theory)
Correspondence: Patrick Henriet Avenue Hippocrate, 75, Bte BI.75.05, 1200 Brussels, Belgium

Tel +3227647545

Fax +3227647543

Email patrick.henriet@uclouvain.be 
or from tissues of nonuterine origin (eg, by metaplasia or development from embryonic remnants). Implantation at ectopic sites relies on mechanisms resembling limited tumor invasion and requires specific processes that include invasiveness, tissue remodeling by local extracellular matrix (ECM) degradation, and interaction of ectopic endometrium with surrounding tissue. ${ }^{3,4}$

EM is characterized by four major features - estrogen dependence, progesterone resistance, ${ }^{5}$ inflammatory response $^{6,7}$ and dysregulation of the immune system ${ }^{8}$ - that are all potentially connected with matrix metalloproteinases (MMPs) and tissue inhibitors of metalloproteinases (TIMPs). MMPs and TIMPs are important players in the cyclic remodeling of the human endometrium and, interestingly, they appear to also contribute to EM development. The purpose of this review is to discuss our current understanding of MMP involvement in EM and whether they represent potential useful biomarkers for diagnosis and/or targets for therapy development.

\section{Hormonal control of the menstrual cycle and of endometriosis}

Between menarche and menopause, the human endometrium undergoes spontaneous cycles of tissue remodeling of its superficial layer, under the global control of ovarian steroids, estrogens and progesterone. During the postmenstrual proliferative phase, estrogens, in particular estradiol, play a critical role in tissue reconstruction by triggering the proliferation of epithelial, stromal, and endothelial cells, thereby inducing thickening of the endometrial superficial layer. After ovulation, progesterone produced by the corpus luteum orchestrates the second phase of the menstrual cycle, the secretory phase, in combination with estradiol. Progesterone opposes the proliferative influence of estrogens and induces cell differentiation to prepare for potential blastocyst implantation. Besides transient modifications of the luminal epithelium to acquire receptivity, progesterone also triggers transformation of the stromal cells into specialized secretory cells, the decidual cells. In the absence of embryo implantation, corpus luteum degeneration results in falling concentration of estrogen and progesterone and induction of menstruation. Of note, spontaneous decidualization (ie, without the need of mating), overt menstruation (with external bleeding) and endometriosis are restricted to a very limited number of mammalian species, essentially Catarrhini (humans, apes, and Old World monkeys).

Common therapies against EM aim at reducing pain and infertility issues. ${ }^{2,9-11}$ Besides surgical resection of the lesions, primary treatments consist of administration of drugs targeting hormone control and/or inflammation. Growth of endometrial cells in ectopic locations still responds to, and depends on, estradiol stimulation. It has been proposed that cells in EM lesions are subjected to additional estradiol supply resulting from local synthesis. In healthy patients, estradiol essentially originates from the ovaries by aromatase-mediated conversion of androstenedione into estrone, followed by a conversion of estrone into estradiol catalyzed by $17 \beta$-hydroxysteroid dehydrogenase type 1 (17B-HSD1). Induction of aromatase expression in the eutopic endometrium and ectopic lesions of women with EM, leading to increased local estradiol concentration favoring lesion growth and implantation, ${ }^{12,13}$ remains controversial. ${ }^{14}$

Most common pharmacological treatments against EM include drugs aimed at reducing estrogen production (danazol) and/or inducing pseudo-menopause (gonadotropin-releasing hormone agonists and antagonists, oral contraceptives, and progestins). In addition, anti-inflammatory actions of progestins help in reducing EM-associated pain. However, danazol in the long-term has hyperandrogenic side effects and, globally, these treatments are inappropriate for patients who want to become pregnant. Moreover, these therapies are not efficient in all patients, in part due to progesterone resistance, ${ }^{5}$ which is interconnected with inflammation. Indeed, EM is characterized by increased production of proinflammatory cytokines, in particular TNF- $\alpha$, not only by cells of the EM lesions but also by cells of the immune system. Enhanced cytokine production is also partially explained by altered progesterone responsiveness resulting from local dysregulation of progesterone receptors. ${ }^{15}$ Moreover, local menstrual-like bleeding of EM lesions also generates an inflammatory response that progressively exacerbates pain.

\section{MMPs and TIMPs in the endometrium of healthy patients}

Most MMPs are expressed in human endometrium. ${ }^{16,17}$ Their functions range from fine tissue remodeling during the proliferative and secretory phases, and in particular during blastocyst implantation, to massive albeit spatially contained ECM breakdown during menstruation. Levels of MMP-1, MMP-3, MMP-8, and MMP-12 mRNAs increase strikingly at the onset of menstruation in response to dropping concentrations of estradiol and progesterone (reviewed by Gaide Chevronnay et $\mathrm{al}^{18}$ ). Expression of MMP-10 increases throughout the mid-late secretory phase to peak at menstruation. ${ }^{16,17,19}$ MMP-1, MMP-3, MMP-8, and MMP-10 
are present essentially in stromal cells, and MMP-1 mRNA is restricted to stromal breakdown foci. ${ }^{17,20,21} \mathrm{MMP}-1$ and MMP-3 proteins localize focally to stromal cells and vascular structures at menstruation. ${ }^{22,23}$ MMP-9 mRNA increases in stromal cells during the menstrual phase, but the protein is found throughout the cycle in stromal, epithelial, and inflammatory cells. ${ }^{16,20,22,24-27}$ MMP-7 and MMP-11 mRNA levels strongly increase at menstruation and subsequently remain elevated during the proliferative phase. ${ }^{16,17,20,28}$ However, while MMP-11 is expressed by stromal cells, MMP-7 is predominantly localized in epithelial cells, but is also found in decidualized cells during the late secretory phase and in stromal foci at menstruation. ${ }^{28}$ In contrast with these MMPs, MMP-2 and MMP-14 mRNA levels are substantial throughout the menstrual cycle and slightly increase at menstruation. ${ }^{16,21,22,29}$ MMP-16 mRNA levels increase during the proliferative phase, whereas expression of MMP-15 and MMP-19 does not vary throughout the cycle. ${ }^{16,17}$ Expression of MMP-26 peaks around ovulation and is strongly decreased at menstruation. ${ }^{16,30,31}$ Expression of TIMP-1 and TIMP-2 is rather constant throughout the cycle, whereas TIMP-3 mRNA is transiently increased during the late secretory and early menstrual phases. ${ }^{16,17,19}$ Temporal regulation of TIMP-4 expression parallels that of MMP-26 and culminates around ovulation. ${ }^{31}$

Progesterone plays a complex role during the secretory phase by preventing expression of MMP-inducing factors (such as cytokines); repressing transcription of MMPs such MMP-1, MMP-3, MMP-7, MMP-8, and MMP-10; and moderately inhibiting MMP-2 and MMP-9 expression, as demonstrated in cultured cells, tissue explants, and in vivo in ovariectomized rhesus monkeys. ${ }^{17,24,32-37}$ Two complementary approaches suggest that MMPs are crucial for initiating menstruation. First, MMP inhibitors, but not inhibitors of other classes of proteases, prevent menstrual-like ECM breakdown in explant culture of human endometrium. Second, adding back progesterone 12 or 24 hours after its withdrawal in ovariectomized rhesus monkeys subjected to artificial menstrual cycle with hormonal implants suppressed expression of (at least) MMP-1, MMP-2, and MMP-3 and blocked menstruation. ${ }^{37}$

However, MMP regulation may locally escape general progesterone repression and generate foci of ECM breakdown and abnormal uterine bleeding, such as in patients on long-term progestin-only contraceptives. Indeed, irregular dysfunctional bleeding episodes are linked with local expression, activation, and uncontrolled activity of several menstrual-associated MMPs including MMP-1, MMP-2,
MMP-3, and MMP-9, as well as with a decreased TIMP-1 expression. $^{38-40}$

\section{MMP and TIMP expression in endometrium and ectopic lesions of endometriotic patients}

Ectopic EM lesions can respond to circulating or locally produced ovarian steroids and grow, differentiate, and undergo menstrual-like tissue breakdown and repair, comparable to the superficial layer of the eutopic endometrium. Since endometrial MMPs play a key role in cyclic menstrual breakdown, and because invasion of endometriotic cells resembles cancer progression, their contribution to disease development was rapidly suspected. During the last 20 years, dozens of studies have consistently reported the presence of MMPs in endometriotic tissue. However, the issue of whether MMP/ TIMP expression is altered in the eutopic endometrium and/or in ectopic lesions of EM patients is still confusing due to the multiplicity of factors that can create diversity in data collection and affect MMP/TIMP expression. Some of these factors are

- The phase of the menstrual cycle at which the sample is collected

- The precise nature of the sample: eutopic endometrium, ectopic endometrium, peritoneal fluid, serum, etc

- The staging of the disease: The American Society for Reproductive Medicine distinguishes four EM stages depending on location, extent, and depth of EM implants; the presence and severity of adhesions; and the presence and size of ovarian EM cysts. ${ }^{41}$ Most women have stage I (minimal) or II (mild) EM, characterized by superficial implants and mild adhesions, whereas stage III (moderate) and IV (severe) EM is characterized by chocolate cysts and more severe adhesions. Infertility is frequent with stage IV EM.

- The location of the ectopic lesion: ovarian, peritoneal, rectovaginal, bowel, etc

- The medical record, especially regarding other uterine disease/symptoms (eg, abnormal bleeding) and (in)fertility issues

- Any drug received by the patient, in particular compounds interfering with ovarian steroids (eg, treatments against EM or infertility, contraception);

- The ability (or not) to experimentally discriminate the various cell types present in the sample (epithelial cells, fibroblasts, endothelial cells, immune/inflammatory cells) and estimate their respective proportions. 


\section{MMP expression in the eutopic endometrium of EM patients}

Rigorous comparison of all publications reporting endometrial MMP expression in EM and non-EM patients would therefore be required to take into account each of these factors of diversity. Here, we rather illustrate the difficulty in identifying systematic changes in MMP/TIMP expression in EM patients that could be used as simple markers to facilitate EM diagnosis.

The most investigated MMPs in the context of EM are MMP-2 and MMP-9. While several studies have reported increased MMP-2 mRNA levels in eutopic endometrium of EM patients in comparison with non-EM patients, ${ }^{42-44}$ others have found similar ${ }^{45}$ or even decreased ${ }^{46}$ MMP-2 immunostaining in eutopic endometrium of EM patients. Most authors have reported increased MMP-9 protein in the eutopic endometrium of EM patients ${ }^{43,47,48}$ but disagreed on the mRNA levels, which were either also increased ${ }^{43}$ or similar ${ }^{47,49}$ in comparison with non-EM patients. Malik et $\mathrm{al}^{50}$ did not find difference of MMP-2 or MMP-9 activity in menstrual effluent between women with and without EM.

Other MMPs have received more limited attention, and so reports of differential expression should be considered with caution. MMP-3 protein was increased in the eutopic endometrium of EM patients for Gilabert-Estelles et al ${ }^{51}$ but decreased for Uzan et al. ${ }^{46}$ MMPs reported to be increased in endometrium of EM patients are MMP-1 (mRNA and protein $^{43}$ ), MMP-14/MT1-MMP (mRNA ${ }^{42}$ ), MMP-16/MT3MMP, ${ }^{52}$ and MMP-7 (in patients with deep infiltrating EM in comparison with patients with superficial peritoneal EM and non-EM patients ${ }^{53,54}$ ).

Accounts on changes in TIMP expression are also controversial, sometimes between publications from a same team, as exemplified by Collette et al, ${ }^{47}$ reporting similar TIMP-1 mRNA and protein levels in the eutopic endometrium of EM patients in disagreement with their previous report of a significant TIMP-1 protein decrease in cultured eutopic endometrium of EM patients, ${ }^{55}$ supported by another study. ${ }^{42}$ Other groups did not evidence differences in TIMP- $1^{46,51}$ or TIMP- $2^{46}$ protein levels, whereas decreased expression of TIMP-3 was also reported. ${ }^{49}$

\section{New insights from whole genome transcriptomic analyses}

Comparisons of whole genome transcriptomes of the eutopic endometrium between EM and non-EM patients have shed new light on potential correlation between the disease and endometrial regulation of MMP expression. A recent study by Tamaresis et $\mathrm{al}^{56}$ is of particular interest. The general aims were to identify molecular differences between endometrium of EM and non-EM patients in order to help in developing new diagnosis biomarkers and/or new strategies for the treatment of associated infertility and pain. After using genomic data from 148 patients categorized according to the phase of the menstrual cycle, and presence and stage of the disease (also distinguishing women with EM from women with uterine/pelvic pathologies different from EM), the authors proposed a diagnosis tree that included three successive binary decisions to separate: 1 ) controls vs uterine diseases (EM or non-EM); 2) EM vs non-EM uterine diseases; and 3) stage I/II vs stage III/IV EM. Surprisingly, at first look, only two members of the MMP/TIMP family are mentioned in the main publication, both for differential expression during the midsecretory phase. MMP-26 is pinpointed for downregulation in EM patients, and TIMP-1 for downregulation in patients with moderate/severe EM in comparison with patients with minimal/mild EM. ${ }^{56}$ Decrease in MMP-26 expression was previously observed in a similar but more limited study by the same group.$^{57}$ Since primary data are publicly available (Gene Expression Omnibus Database: entry GSE51981), we selectively reanalyzed values for the MMP and TIMP probe sets and compared the 4 disease groups (control, non-EM uterine/pelvic disease, stage I/II EM, and stage III/IV EM) separately for each cycle phase documented (proliferative, early secretory, and mid-secretory). We made two striking observations (Figures 1 and 2). First, statistical analysis (ANOVA followed by Dunn's multiple comparison) did not provide support to differential expression of common endometrial MMPs (MMP-1, MMP-2, MMP-3, MMP-7, MMP-9, MMP-10, MMP-14) in the eutopic endometrium of EM patients in comparison with non-EM patients (Figure 1). However, we acknowledge that segregation of patients according to multiple parameters drastically reduced group sizes and negatively influenced statistical evaluation. Second, and most importantly, comparing the individual profiles of MMP expression highlighted the presence of remarkable outlier patients in most groups regardless of the disease and of the cycle phase (Figure 2). These patients present substantial and often coordinated overexpression of MMP-1, MMP-3, MMP-7, MMP-9, MMP-10, and/or MMP-12, similar to expression peaks observed in normal menstrual endometrium, ${ }^{16,17}$ therefore suggesting that the eutopic endometrium of these patients is undergoing (or prepared to undergo) an episode of (local) ECM breakdown that escaped clinical evaluation. 

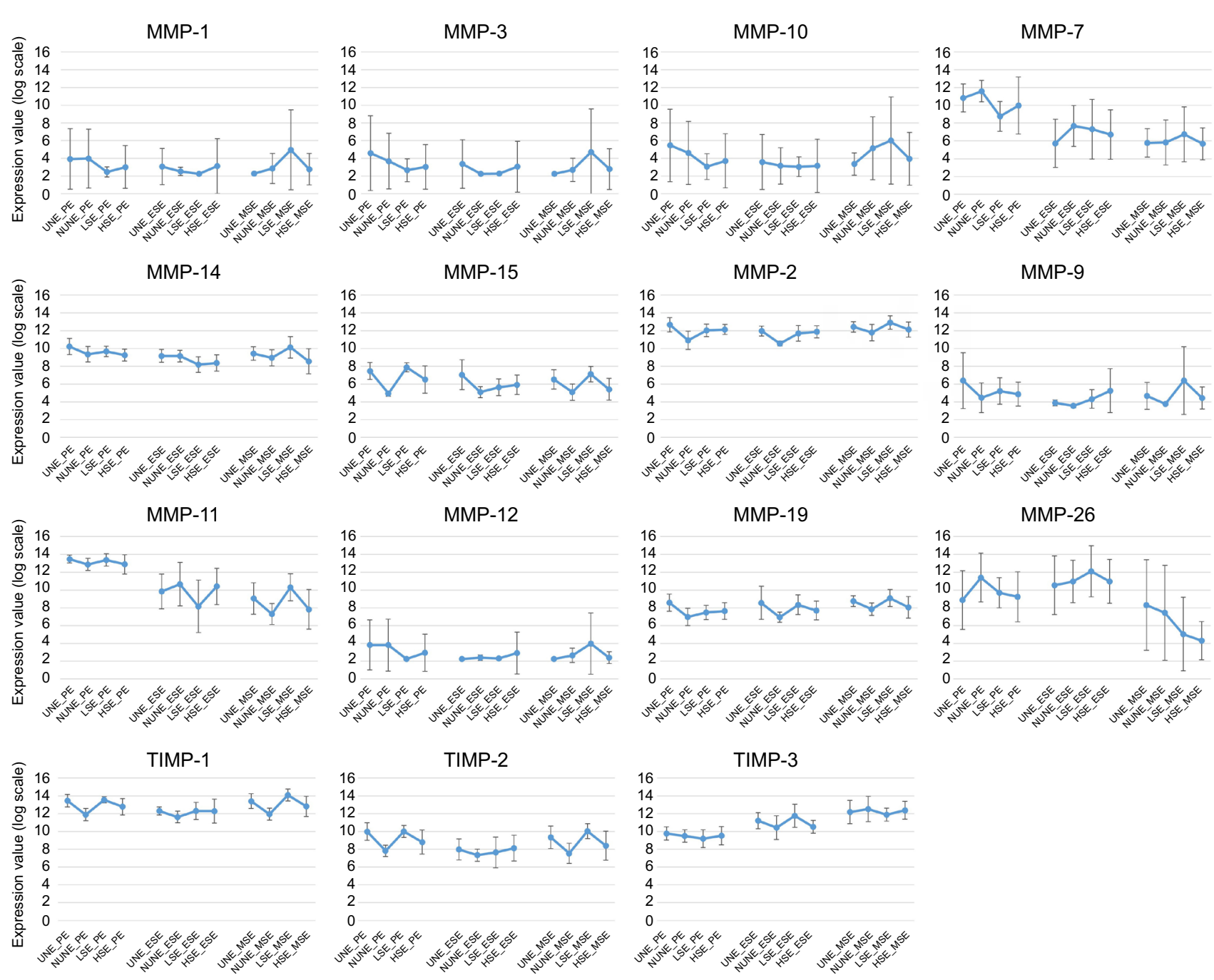

Figure I Comparison of eutopic MMP and TIMP expression between EM and non-EM patients.

Notes: Values from selected MMP and TIMP probe sets were retrieved from Gene Expression Omnibus Database entry GSE5I98I and were grouped according to phases of the menstrual cycle and type and stage of the disease. Data are presented as mean \pm SD. For more information about the experimental procedure, refer to Gene Expression Omnibus. Available from: https://www.ncbi.nlm.nih.gov/geo/query/acc.cgi?acc=GSE5I98I. Accessed July 25, 2016,121 data from Tamaresis et al. ${ }^{56}$

Abbrevations: UNE, uterine/pelvic disease, no EM; NUNE, no uterine/pelvic disease, no EM; LSE, low stage EM; HSE, high stage EM; PE, proliferative endometrium; ESE, early secretory endometrium; MSE, mid-secretory endometrium; MMPs, matrix metalloproteinases; TIMPs, tissue inhibitors of metalloproteinases; SD, standard deviation.

Although the exact cause of such a surge in expression of selected MMPs remains to be explained, it is obviously not correlated with presence of a specific uterine disease, EM stage, or phase of the menstrual cycle (outside menstruation).

As previously reported, ${ }^{30} \mathrm{MMP}-26$ expression is elevated in most samples during the proliferative and early secretory phases. However, the mid-secretory phase is characterized by larger individual variations, regardless of the disease (Figure 2), suggesting progressive reduction toward minimal values reached during the late secretory phase. ${ }^{30}$ Most interestingly, MMP-26 expression seems to inversely correlate with expression of MMP-1 and MMP-3, and this is particularly emphasized by the outlier samples for which unexplained peaking expression of MMP-1 and MMP-3 is accompanied with striking downregulation of MMP-26 expression, again regardless of the phase or the disease.

In conclusion, due to the absence of systematic dysregulation of MMP/TIMP mRNA levels associated with EM, and in fear of confusion with yet unexplained occasional strong MMP dysregulation, we strongly recommend not to use values of MMP expression in the eutopic endometrium as classifiers to identify EM patients.

\section{MMP expression in ectopic lesions}

Differential expression of MMPs and TIMPs in ectopic lesions is also subject to conflicting reports. Most publications describe increased MMP expression by comparison with 


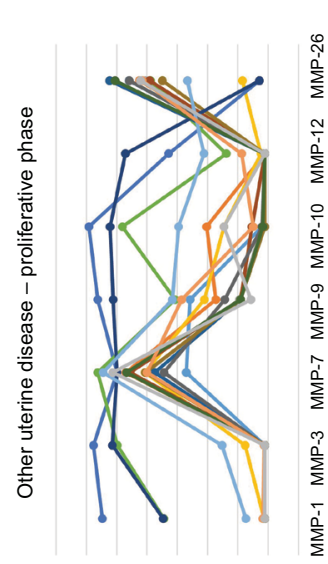

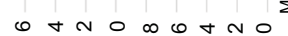
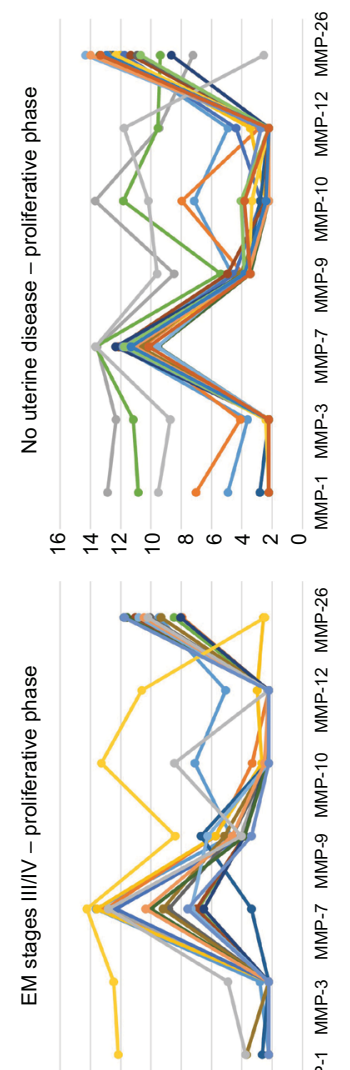

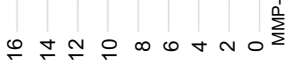

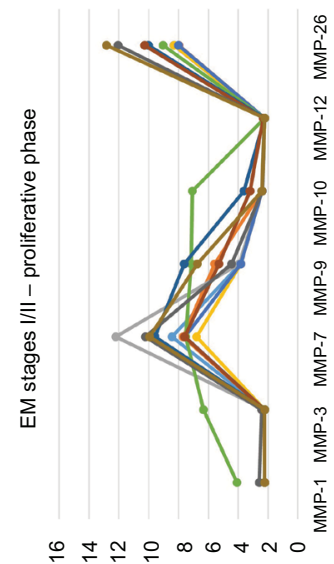

(ә|еоs 6о) әп|е^ uo!ssəıdxヨ

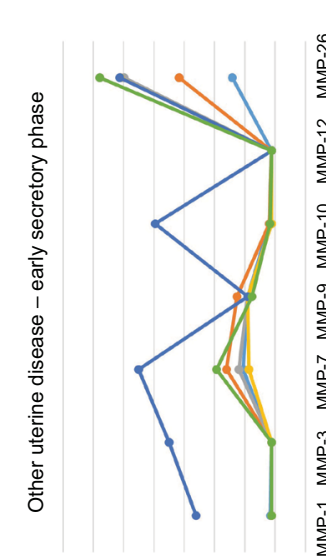

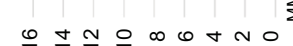
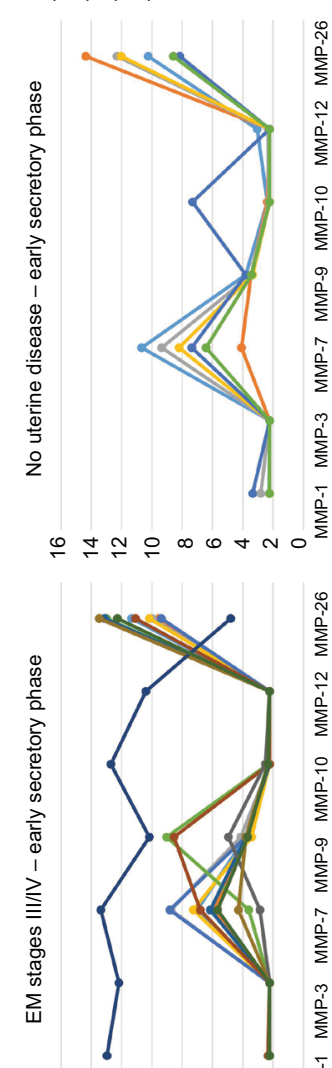

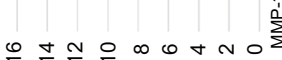

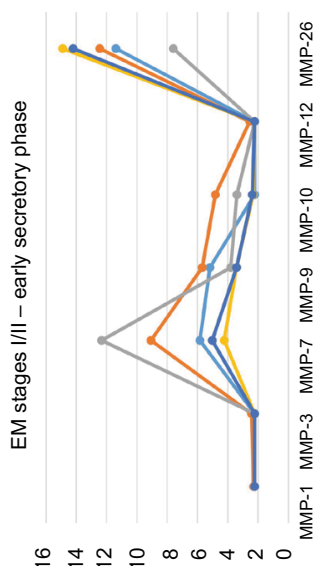

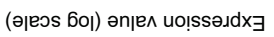
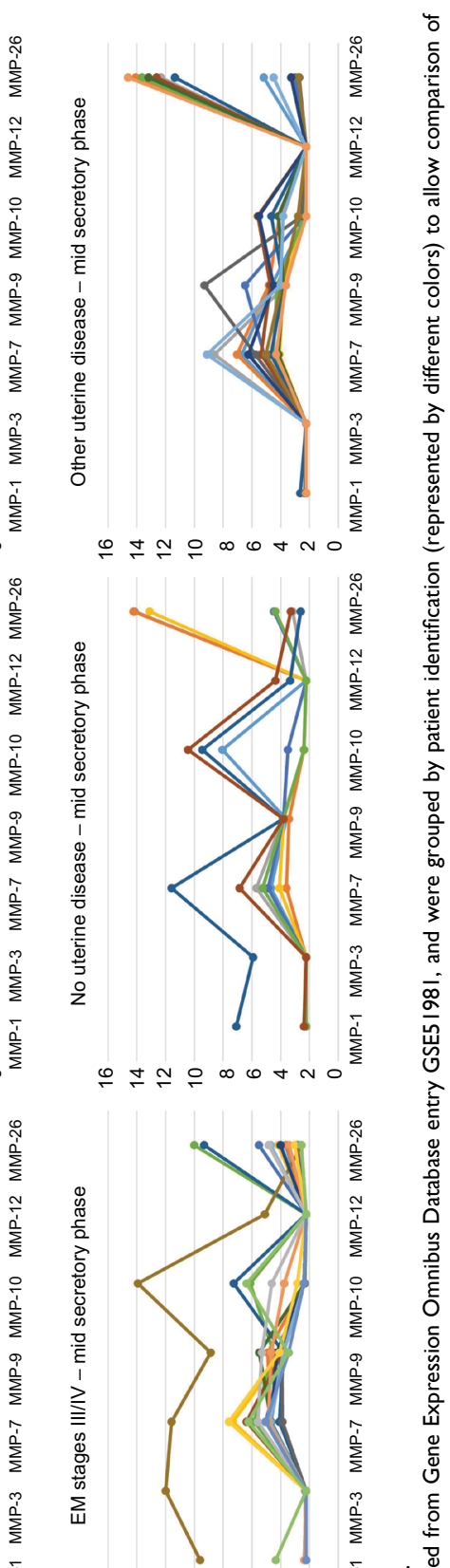

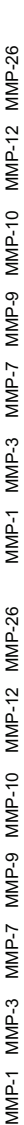

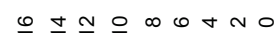

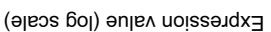

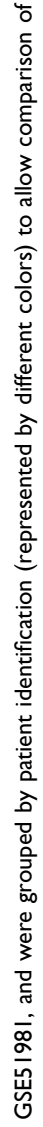

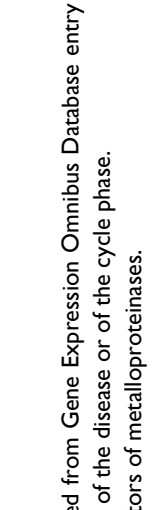

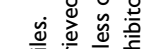

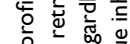

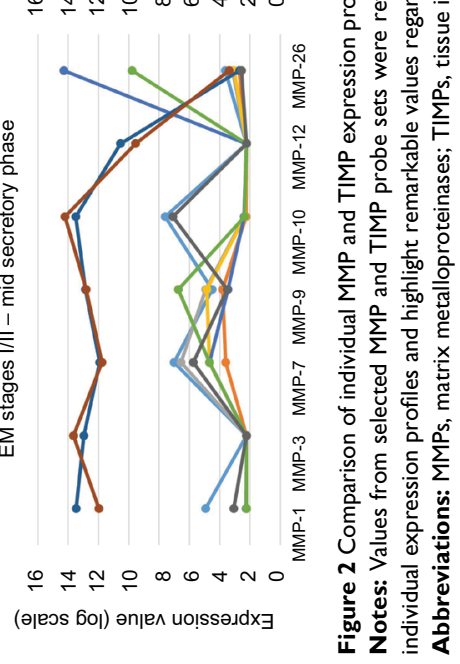


eutopic endometrium, eg, for MMP-1, ${ }^{43,58-60}$ MMP-2, ${ }^{43-45,60}$ and MMP- $9^{43,49,60}$ and decreased expression of TIMP-1 and TIMP-2. ${ }^{59}$ However, other studies report low or decreased ectopic expression of MMP-2, ${ }^{42,46}$ MMP-3, ${ }^{46,51}$ increased expression of TIMP- $1{ }^{51}$ and TIMP-2, ${ }^{46}$ or absence of significant difference between eutopic and ectopic endometrium for MMP-2, MMP-3, MMP-9, ${ }^{48,59}$ and MMP-7. ${ }^{53}$ MMP expression seems to vary according to the location of the lesion. For instance, we localized MMP-1 mRNA in foci of ECM breakdown in red peritoneal and ovarian endometriosis irrespective of the menstrual cycle but did not detect it in black peritoneal and rectovaginal lesions. ${ }^{61}$ Uzan et $\mathrm{al}^{46}$ found more abundant immunostaining of MMP-2, MMP-3, and MMP-11 in colorectal EM than in peritoneal and ovarian EM and increased TIMP-2 immunostaining in peritoneal EM in comparison with ovarian EM cysts and colorectal EM. For Matsuzaki et al, ${ }^{54} \mathrm{MMP}-7$ protein levels were significantly higher in red peritoneal lesions in comparison with deep infiltrating EM, ovarian EM, and black peritoneal lesions in all phases of the menstrual cycle. MMP-2 immunostaining was increased in invasive colorectal EM in comparison with superficial peritoneal EM. ${ }^{62}$ Recently, we found MMP-27 immunolabeling in superficial peritoneal and ovarian lesions but not in deep infiltrating rectovaginal lesions. ${ }^{63}$

At least three studies compared whole genome transcriptomes between paired ectopic and eutopic endometrium from EM patients. ${ }^{64-66}$ Regarding MMP expression, the most striking and reproducible differences only point to MMP-26 and MMP-23. Indeed MMP-26 is systematically expressed at very low levels in peritoneal and ovarian ectopic lesions, even when its mRNA levels are elevated in the corresponding eutopic endometrium. These analyses also suggest substantial increase of MMP-23 expression in ectopic lesions (not shown; see MMP-26 and MMP-23 expression profile in Gene Expression Omnibus Database entries GDS2825 and GDS3092).

\section{MMP expression in peritoneal fluid and serum}

Studies were performed to determine whether levels of MMPs in body fluids could help our understanding of disease progression (peritoneal fluid) and/or facilitate EM diagnosis (serum). They suggest increased levels of MMP-2 ${ }^{67,68}$ and total MMP- ${ }^{69}$ and decreased TIMP-2 levels ${ }^{68}$ in the peritoneal fluid of EM patients, without significant difference for MMP-3 and TIMP-1 levels. ${ }^{51}$ Increased levels of MMP-2 $2^{68,70}$ or MMP $-3^{71}$ were also detected in the serum of EM patients. However, these results need to be confirmed with larger patient numbers. Moreover serum values of MMPs in EM patients must be compared to values collected from outlier patients (Figure 2) at the time of exceptional MMP expression in their endometrium.

\section{Genetic polymorphism}

The exact causes of EM are still unknown but could be due to multiple factors. Canis et $\mathrm{al}^{72}$ recently questioned whether endometriosis is a progressive and/or inevitably recurrent disease. They collected a series of clinical evidences providing additional support to a previous hypothesis that trauma may induce or contribute to EM. ${ }^{73}$ Indeed, wound healing resulting from severe trauma (postsurgery) or minimal trauma (eg, ovarian ovulation scar) involves local mechanical stress; MMP-mediated ECM remodeling; ${ }^{74,75}$ and production of growth factors, $\mathrm{PGE}_{2}$, and aromatase, all of which may together facilitate lesion implantation and growth.

Higher rates of EM among relatives of EM patients suggest that genetic variants confer inheritable susceptibility to develop the disease. Hypothesis-based and hypothesis-free methods were used for the identification and investigation of genetic variants underlying EM (reviewed in Rahmioglu et $\mathrm{al}^{76}$ and Trovó de Marqui ${ }^{77}$ papers). Hypothesis-free approaches, targeting the whole genome without gene preselection, have not retained genes encoding MMPs and TIMPs thus far. On the other hand, hypothesis-based approaches focused on genes encoding MMPs underlined a short list of genetic variants, alleles, and haplotypes associated with increased risk for developing EM for MMP-1, ${ }^{78} \mathrm{MMP}-2,{ }^{79}$ MMP-9, ${ }^{79,80}$ and TIMP-2. ${ }^{81}$ Other studies identified variants or haplotypes associated with reduced risk for MMP- $2^{81}$ and TIMP-2. ${ }^{81,82}$

Three studies suggest association between genetic variants at the interleukin- $1 \alpha$ (IL- $1 \alpha)$ gene locus and endometriosis risk. ${ }^{83-85}$ Further investigation should definitely address whether these mutations involve changes in MMP expression since we have previously shown that 1) IL-1 $\alpha$ is upregulated in the endometrium during menstruation or abnormal uterine bleeding episodes and 2) at menstruation, IL-1 $\alpha$ secreted by epithelial cells induces MMP-1 expression by stromal fibroblasts. ${ }^{38,86,87}$ Moreover, IL-1 $\alpha$ and MMP-1 are coexpressed in the stroma of endometriotic foci. ${ }^{58}$

Potential association between EM and genetic variants in MMP genes or their potential regulators requires further validation with larger cohorts. Moreover, the mechanisms by which these mutations would affect MMP expression and/or activity during EM development remains to be clarified. 


\section{MMPs and TIMPs in animal models of artificial endometriosis}

As illustrated in Figure 2, whole genome characterization of endometrial transcriptomes indicates that individual variations overcome systematic differential expression of endometrial MMPs between EM and non-EM patients. However, since MMPs are physiologically expressed in the endometrium, their contribution to EM pathogenesis does not specifically require differential expression and just depends on opportune production. Proinvasive and proangiogenic roles of MMPs in endometriosis have been demonstrated in cell culture, in particular by culturing on chorioallantoic membrane of chick embryos. ${ }^{88-90}$ But above all, in vivo animal models have allowed advances in our understanding of the regulation and role of MMPs during lesion development. ${ }^{91}$ In common rodent models, fragments of human or self-endometrium are injected into the peritoneal cavity or implanted onto the peritoneum of ovariectomized and immune-deprived animals. Functional involvement of MMPs in artificial EM was suggested in the early days of MMP investigation, two decades ago, when Bruner et $\mathrm{al}^{92}$ showed that pretreatment of endometrial fragments and/or in vivo injection of recombinant TIMP-1 significantly reduced the development of induced ectopic lesions in mice.

Since then, numerous studies using rodent models have largely and repeatedly recorded local and transient (over) expression of MMPs during the development of ectopic lesions, in particular MMP-2, ${ }^{44,93-101}$ MMP-9,,${ }^{97,99,101-107}$ and MMP-3. ${ }^{93,94,100,103,108,109}$ MMP-2 overexpression was often associated with reduced expression of TIMP-2, ${ }^{44,93,104}$ but not systematically. ${ }^{98}$ Progestins can repress MMP expression in ectopic lesions. ${ }^{94}$ Moreover, in a model of human endometrium transplanted subcutaneously in ovariectomized mice, we have shown that menstrual-like MMP expression and ECM breakdown are induced in xenografts after removal of pellets delivering estradiol and progesterone. ${ }^{110,111}$

Due to the urgent need for alternative and more focused treatments against EM, with less adverse secondary effects, novel nonhormonal drugs have been tested and have been shown to be effective in the reduction of EM implants in rodent models. These drugs essentially target pathways involved in inflammation and angiogenesis (reviewed by Platteeuw and $\mathrm{D}^{\prime} \mathrm{Hooghe}^{112}$ ). Some studies have simultaneously questioned MMP expression and the ability of drugs to reduce EM development in these animal models of artificial EM.

Administration of curcumin, a natural polyphenol with anti-inflammatory properties, delayed endometriotic progression, inhibited NF- $\mathrm{\kappa B}$ translocation, accelerated apoptosis, and downregulated MMP-3 and MMP-14 expression and proMMP-2 activation. ${ }^{93,113}$

The p38 MAPK is a regulator of inflammation and may play a role in EM pathogenesis. In a mouse model of intraperitoneal injection of endometrium fragments, p38 phosphorylation was increased in peritoneal cells. SB203580, a p38 inhibitor, decreased mRNA and protein levels of MMP-2 and MMP-9 and reduced the size and weight of EM lesions. ${ }^{97}$ Bentamapimod (AS602801), a JNK pathway inhibitor, reduced inflammatory cytokine production in two rodent EM models, and, when combined with medroxyprogesterone acetate, caused regression of the lesions in vivo and reduced MMP-3 production in explants..$^{109}$

Expression of macrophage migration inhibitory factor (MIF) is markedly increased in the eutopic endometrium, the peritoneal fluid, and the peripheral blood of women with EM and in early, vascularized, and active EM lesions. ${ }^{114}$ Administration of ISO-1, a MIF inhibitor, decreased the number and size of induced peritoneal EM lesions and reduced expression of MMP-2, MMP-9, VEGF, IL-8, and COX2. ${ }^{96}$

EM is often associated with a pelvic immune-inflammatory process and with imbalance between IL-1 and its natural inhibitor IL1R2. It was shown that soluble IL1R2 (sIL1R2) interferes with the capability of EM tissue to invade, grow, disseminate, and stimulate angiogenesis in the host tissue in an in vivo model in which human endometrial tissue was inoculated into nude mice. Of particular interest, sIL1R2 downregulated MMP-2, MMP-9, and VEGF and upregulated TIMP-1 and TIMP-2. ${ }^{95}$

Metformin, a widely used antidiabetic drug inhibiting proliferation, proinflammatory cytokine production, and aromatase activation in endometriotic stromal cells, ${ }^{115}$ reduced endometriotic implants volume and MMP-9 production in a rat model, while increasing TIMP-2 levels. ${ }^{104}$

Targeted intravenous delivery of interleukin-4 in a mouse model of EM reduced expression of MMP-3 and MMP-9, and the number and volume of lesions. ${ }^{103}$ Resveratrol (a polyphenol) and leuprolide acetate (an agonist of the gonadotrophin-releasing hormone) reduced implant volume and immunoreactivity for MMP-2, MMP-9, and VEGF in a rat EM model. ${ }^{99}$ Statins have antiproliferative, antiangiogenic, antioxidant, and anti-inflammatory properties, in addition to their ability to inhibit MMPs. ${ }^{116}$ Two studies with simvastatin showed reduction of MMP-2 and/or MMP-3 expression in induced EM lesions ${ }^{100,117}$ whereas atorvastatin reduced expression of MMP-9 and VEGF and increased TIMP-2 in a rat model. ${ }^{118}$ Propranolol (a $\beta$-adrenergic receptor-blocker) reduced implant size and MMP-2, MMP-9, and VEGF 
immunoreactivity in a rat model. ${ }^{101}$ Lipoxin A4 (arachidonic acid derivative with immunomodulatory and anti-inflammatory actions) attenuated the invasive activity of EM stromal cells by suppressing expression and activity of MMP-9 and inhibited EM progression in vivo. ${ }^{105,106}$ Administration of vitamin 1,25(OH) 2 D3 reduced implant size and MMP-9 and VEGF immunoreactivity, while increasing TIMP-2 immunoreactivity in a mouse model. ${ }^{107}$ Gene therapy with the antiangiogenic endostatin (transfection by intralesional injection) in a rat model reduced lesion size and MMP-2 levels. ${ }^{119}$

Although initial infatuation for the development of therapeutic MMP inhibitors, especially against cancer, strongly declined due to the deleterious side effects of broad-spectrum peptidomimetic inhibitors, there is now renewed interest for novel, highly selective agents, ranging from small molecules to antibodies, antisense inhibitors, and engineered $N$-terminal tissue inhibitors of metalloproteinase domain (remarkably reviewed by Mohan et $\mathrm{al}^{120}$ ). To gain further insight into the precise role of MMPs in EM and to better evaluate their potential as therapeutic targets, future investigations aimed at testing the effects of these new substances on EM development or progression are urgently needed.

In conclusion, MMPs and TIMPs are present in eutopic and ectopic endometrium of EM patients, but the difficulty in identifying systematic MMP/TIMP differential regulation associated with the disease, combined with occasional and unexplained eutopic overexpression of selective MMPs regardless of the disease and phase of the menstrual cycle, does not support their use as diagnosis biomarkers. On the other hand, MMP contribution to EM development and progression is strongly supported by animal models and clearly deserves further investigation, especially in light of the recent advances on new MMP inhibitors.

\section{Acknowledgment}

This work was supported by grants from the Fonds de la Recherche Scientifique (FRS-FNRS, Belgium). $\mathrm{PH}$ is a Research Associate at FRS-FNRS.

\section{Disclosure}

The authors report no conflicts of interest in this work.

\section{References}

1. Burney RO, Giudice LC. Pathogenesis and pathophysiology of endometriosis. Fertil Steril. 2012;98(3):511-519.

2. Vercellini P, Viganò P, Somigliana E, Fedele L. Endometriosis: pathogenesis and treatment. Nat Rev Endocrinol. 2013;10(5):261-275.

3. Giudice LC, Kao LC. Endometriosis. Lancet. 2004;364(9447): 1789-1799.
4. Hull ML, Escareno CR, Godsland JM, et al. Endometrial-peritoneal interactions during endometriotic lesion establishment. Am J Pathol. 2008;173(3):700-715.

5. Al-Sabbagh M, Lam EW, Brosens JJ. Mechanisms of endometrial progesterone resistance. Mol Cell Endocrinol. 2012;358(2): 208-215.

6. Taylor RN, Kane MA, Sidell N. Pathogenesis of endometriosis: roles of retinoids and inflammatory pathways. Semin Reprod Med. 2015;33(4):246-256.

7. Nothnick W, Alali Z. Recent advances in the understanding of endometriosis: the role of inflammatory mediators in disease pathogenesis and treatment. F1000Research. 2016;5:1-9.

8. Ahn SH, Monsanto S, Miller C, Singh S, Thomas R, Tayade C. Pathophysiology and immune dysfunction in endometriosis. Biomed Res Int 2015;2015:1-12.

9. Brown J, Farquhar C. An overview of treatments for endometriosis. JAMA. 2015;313(3):296-297.

10. Schrager S, Falleroni J, Edgoose J. Evaluation and treatment of endometriosis. Am Fam Physician. 2013;87(2):107-113.

11. Quaas AM, Weedin EA, Hansen KR. On-label and off-label drug use in the treatment of endometriosis. Fertil Steril. 2015;103(3):612-625.

12. Bulun SE, Yang S, Fang Z, et al. Role of aromatase in endometrial disease. J Steroid Biochem Mol Biol. 2001;79(1-5):19-25.

13. Bulun SE. Endometriosis. N Engl J Med. 2009;360(3):268-279.

14. Colette $S$, Lousse JC, Defrère $S$, et al. Absence of aromatase protein and mRNA expression in endometriosis. Hum Reprod. 2009;24(9): 2133-2141.

15. Attia GR, Zeitoun K, Edwards D, Johns A, Carr BR, Bulun SE. Progesterone receptor isoform $\mathrm{A}$ but not $\mathrm{B}$ is expressed in endometriosis J Clin Endocrinol Metab. 2000;85(8):2897-2902.

16. Goffin F, Munaut C, Frankenne F, et al. Expression pattern of metalloproteinases and tissue inhibitors of matrix-metalloproteinases in cycling human endometrium. Biol Reprod. 2003;69(3):976-984.

17. Vassilev V, Pretto CM, Cornet PB, et al. Response of matrix metalloproteinases and tissue inhibitors of metalloproteinases messenger ribonucleic acids to ovarian steroids in human endometrial explants mimics their gene- and phase-specific differential control in vivo. J Clin Endocrinol Metab. 2005;90(10):5848-5857.

18. Gaide Chevronnay HP, Selvais C, Emonard H, Galant C, Marbaix E, Henriet $P$. Regulation of matrix metalloproteinases activity studied in human endometrium as a paradigm of cyclic tissue breakdown and regeneration. Biochim Biophys Acta. 2012;1824(1):146-156.

19. Hampton AL, Salamonsen LA. Expression of messenger-ribonucleicacid encoding matrix metalloproteinases and their tissue inhibitors is related to menstruation. J Endocrinol. 1994;141(1):R1-R3.

20. Rodgers WH, Matrisian LM, Giudice LC, et al. Patterns of matrix metalloproteinase expression in cycling endometrium imply differential functions and regulation by steroid hormones. J Clin Invest. 1994;94(3): 946-953.

21. Kokorine I, Marbaix E, Henriet P, et al. Focal cellular-origin and regulation of interstitial collagenase (matrix metalloproteinase-1) are related to menstrual breakdown in the human endometrium. $J$ Cell Sci. 1996;109:2151-2160.

22. Freitas S, Meduri G, Le Nestour E, Bausero P, Perrot-Applanat M. Expression of metalloproteinases and their inhibitors in blood vessels in human endometrium. Biol Reprod. 1999;61(4):1070-1082.

23. Henriet $\mathrm{P}$, Cornet $\mathrm{PB}$, Lemoine $\mathrm{P}$, et al. Circulating ovarian steroids and endometrial matrix metalloproteinases (MMPs). Ann N Y Acad Sci. 2002;955:119-138.

24. Cornet PB, Galant C, Eeckhout Y, Courtoy PJ, Marbaix E, Henriet P. Regulation of matrix metalloproteinase-9/gelatinase $B$ expression and activation by ovarian steroids and LEFTY-A/endometrial bleedingassociated factor in the human endometrium. J Clin Endocrinol Metab. 2005;90(2):1001-1011.

25. Rigot V, Marbaix E, Lemoine P, Courtoy PJ, Eeckhout Y. In vivo perimenstrual activation of progelatinase $\mathrm{B}$ (proMMP-9) in the human endometrium and its dependence on stromelysin 1 (MMP-3) ex vivo. Biochem J. 2001;358(Pt 1):275-280. 
26. Jeziorska M, Nagase H, Salamonsen LA, Woolley DE. Immunolocalization of the matrix metalloproteinases gelatinase $\mathrm{B}$ and stromelysin 1 in human endometrium throughout the menstrual cycle. J Reprod Fertil. 1996;107:43-51.

27. Skinner JL, Riley SC, Gebbie AE, Glasier AF, Critchley HO. Regulation of matrix metalloproteinase- 9 in endometrium during the menstrual cycle and following administration of intrauterine levonorgestrel. Hum Reprod. 1999;14(3):793-799.

28. Rodgers WH, Osteen KG, Matrisian LM, Navre M, Giudice LC, Gorstein F. Expression and localization of matrilysin, a matrix metalloproteinase, in human endometrium during the reproductive cycle. Am J Obstet Gynecol. 1993;168(1):253-260.

29. Irwin JC, Kirk D, Gwatkin RB, Navre M, Cannon P, Giudice LC. Human endometrial matrix metalloproteinase-2, a putative menstrual proteinase. J Clin Invest. 1996;97(2):438-447.

30. Pilka R, Whatling C, Domanski H, Hansson S, Erriksson P, Casslén B. Epithelial expression of matrix metalloproteinase-26 is elevated at midcycle in the human endometrium. Mol Hum Reprod. 2003;9(5):271-277.

31. Pilka R, Domanski H, Hansson S, Eriksson P, Casslén B. Endometrial TIMP-4 mRNA is high at midcycle and in hyperplasia, but downregulated in malignant tumours. Coordinated expression with MMP26. Mol Hum Reprod. 2004;10(9):641-650.

32. Marbaix E, Donnez J, Courtoy PJ, Eeckhout Y. Progesterone regulates the activity of collagenase and related gelatinases A and B in human endometrial explants. Proc Natl Acad Sci U S A. 1992;89(24):11789-11793.

33. Marbaix E, Kokorine I, Henriet P, Donnez J, Courtoy PJ, Eeckhout Y. The expression of interstitial collagenase in human endometrium is controlled by progesterone and by oestradiol and is related to menstruation. Biochem J. 1995;305:1027-1030.

34. Osteen KG, Rodgers WH, Gaire M, Hargrove JT, Gorstein F, Matrisian LM. Stromal-epithelial interaction mediates steroidal regulation of metalloproteinase expression in human endometrium. Proc Natl Acad Sci U S A. 1994;91(21):10129-10133.

35. Schatz F, Papp C, Toth-Pal E, Lockwood CJ. Ovarian steroid-modulated stromelysin-1 expression in human endomtrial stromal and decidual cells. J Clin Endocrinol Metab. 1994;78(6):1467-1472.

36. Salamonsen LA, Butt AR, Hammond FR, Garcia S, Zhang J. Production of endometrial matrix metalloproteinases, but not their tissue inhibitors, is modulated by progesterone withdrawal in an in vitro model for menstruation. J Clin Endocrinol Metab. 1997;82(5):1409-1415.

37. Slayden OD, Brenner RM. A critical period of progesterone withdrawal precedes menstruation in macaques. 2006;10:1-10.

38. Galant C, Vekemans M, Lemoine P, et al. Temporal and spatial association of matrix metalloproteinases with focal endometrial breakdown and bleeding upon progestin-only contraception. J Clin Endocrinol Metab. 2000;85(12):4827-4834.

39. Galant $\mathrm{C}$, Berlière $\mathrm{M}$, Dubois $\mathrm{D}$, et al. Focal expression and final activity of matrix metalloproteinases may explain irregular dysfunctional endometrial bleeding. Am J Pathol. 2004;165(1):83-94.

40. Labied S, Galant C, Nisolle M, et al. Differential elevation of matrix metalloproteinase expression in women exposed to levonorgestrelreleasing intrauterine system for a short or prolonged period of time. Hum Reprod. 2009;24(1):113-121.

41. American Society for Reproductive Medicine. Endometriosis: a guide for patients. Patient Inf Ser. 2012;60:1-8.

42. Chung HW, Lee JY, Moon HS, et al. Matrix metalloproteinase-2, membranous type 1 matrix metalloproteinase, and tissue inhibitor of metalloproteinase-2 expression in ectopic and eutopic endometrium. Fertil Steril. 2002;78(4):787-795.

43. Di Carlo C, Bonifacio M, Tommaselli GA, Bifulco G, Guerra G, Nappi C. Metalloproteinases, vascular endothelial growth factor, and angiopoietin 1 and 2 in eutopic and ectopic endometrium. Fertil Steril. 2009;91(6):2315-2323.

44. Sotnikova NY, Antsiferova YS, Posiseeva LV, Shishkov DN, Posiseev DV, Filippova ES. Mechanisms regulating invasiveness and growth of endometriosis lesions in rat experimental model and in humans. Fertil Steril. 2010;93(8):2701-2705.
45. Wenzl RJ, Heinzl H. Localization of matrix metalloproteinase-2 in uterine endometrium and ectopic implants. Gynecol Obstet Invest. 1998;45(4):253-257.

46. Uzan C, Cortez A, Dufournet C, Fauvet R, Siffroi JP, Daraï E. Eutopic endometrium and peritoneal, ovarian and bowel endometriotic tissues express a different profile of matrix metalloproteinases-2, -3 and -11 , and of tissue inhibitor metalloproteinases-1 and -2. Virchows Arch. 2004;445(6):603-609.

47. Collette T, Maheux R, Mailloux J, Akoum A. Increased expression of matrix metalloproteinase-9 in the eutopic endometrial tissue of women with endometriosis. Hum Reprod. 2006;21(12):3059-3067.

48. Pan H, Sheng JZ, Tang L, Zhu R, Zhou TH, Huang HF. Increased expression of c-fos protein associated with increased matrix metalloproteinase-9 protein expression in the endometrium of endometriotic patients. Fertil Steril. 2008;90(4):1000-1007.

49. Chung HW, Wen Y, Chun SH, Nezhat C, Woo BH, Lake Polan M. Matrix metalloproteinase-9 and tissue inhibitor of metalloproteinase-3 mRNA expression in ectopic and eutopic endometrium in women with endometriosis: a rationale for endometriotic invasiveness. Fertil Steril. 2001;75(1):152-159.

50. Malik S, Day K, Perrault I, Charnock-Jones DS, Smith SK. Reduced levels of VEGF-A and MMP-2 and MMP-9 activity and increased TNF-alpha in menstrual endometrium and effluent in women with menorrhagia. Hum Reprod. 2006;21(8):2158-2166.

51. Gilabert-Estelles J, Estelles A, Gilabert J, et al. Expression of several components of the plasminogen activator and matrix metalloproteinase systems in endometriosis. Hum Reprod. 2003;18(7):1516-1522.

52. Chung HK, Lee JY, Jeong KA, Chung HW. Expression of membrane type-2 and -3 matrix metalloproteinases in eutopic endometrium of women with advanced endometriosis. 2011;54(8):441-447.

53. Matsuzaki S, Canis M, Vaurs-Barrière $\mathrm{C}$, et al. DNA microarray analysis of gene expression profiles in deep endometriosis using laser capture microdissection. Mol Hum Reprod. 2004;10(10): 719-728.

54. Matsuzaki S, Maleysson E, Darcha C. Analysis of matrix metalloproteinase-7 expression in eutopic and ectopic endometrium samples from patients with different forms of endometriosis. Hum Reprod. 2010;25(3):742-750.

55. Collette T, Bellehumeur C, Kats R, et al. Evidence for an increased release of proteolytic activity by the eutopic endometrial tissue in women with endometriosis and for involvement of matrix metalloproteinase-9. Hum Reprod. 2004;19(6):1257-1264.

56. Tamaresis JS, Irwin JC, Goldfien GA, et al. Molecular classification of endometriosis and disease stage using high-dimensional genomic data. Endocrinology. 2014;155(12):4986-4999.

57. Burney RO, Talbi S, Hamilton AE, et al. Gene expression analysis of endometrium reveals progesterone resistance and candidate susceptibility genes in women with endometriosis. Endocrinology. 2007;148(8):3814-3826.

58. Hudelist G, Lass H, Keckstein J, et al. Interleukin 1 alpha and tissue-lytic matrix metalloproteinase-1 are elevated in ectopic endometrium of patients with endometriosis. Hum Reprod. 2005;20(6): 1695-1701.

59. Gottschalk C, Malberg K, Arndt M, et al. Matrix metalloproteinases and TACE play a role in the pathogenesis of endometriosis. In: Langner $\mathrm{J}$, Ansorge S, editors. Cellular Peptidases in Immune Functions and Diseases 2. New York, NY: Kluwer Academic/Plenum Publishers; 2000:483-486.

60. Mizumoto H, Saito T, Ashihara K, et al. Expression of matrix metalloproteinases in ovarian endometriomas: immunohistochemical study and enzyme immunoassay. Life Sci. 2002;71:259-273.

61. Kokorine I, Eeckhout Y, Nisolle M, Courtoy PJ, Donnez J, Marbaix E. Expression of interstitial collagenase (matrix metalloproteinase-1) is related to the activity of human endometriotic lesions. Fertil Steril. 1997;68(2):246-251.

62. Weigel MT, Kramer J, Schem C, et al. Differential expression of MMP2, MMP-9 and PCNA in endometriosis and endometrial carcinoma. Eur J Obstet Gynecol Reprod Biol. 2012;160(1):74-78. 
63. Cominelli A, Gaide Chevronnay HP, Lemoine P, Courtoy PJ, Marbaix E, Henriet P. Matrix metalloproteinase-27 is expressed in CD163+/CD206+M2 macrophages in the cycling human endometrium and in superficial endometriotic lesions. Mol Hum Reprod. 2014;20(8):767-775.

64. Eyster KM, Klinkova O, Kennedy V, Hansen KA. Whole genome deoxyribonucleic acid microarray analysis of gene expression in ectopic versus eutopic endometrium. Fertil Steril. 2007;88(6):1505-1533.

65. Hever A, Roth RB, Hevezi P, et al. Human endometriosis is associated with plasma cells and overexpression of B lymphocyte stimulator. Proc Natl Acad Sci U S A. 2007;104(30):12451-12456.

66. Borghese B, Mondon F, Noël JC, et al. Gene expression profile for ectopic versus eutopic endometrium provides new insights into endometriosis oncogenic potential. Mol Endocrinol. 2008;22(11) 2557-2562.

67. Huang HF, Hong LH, Tan Y, Sheng JZ. Matrix metalloproteinase 2 is associated with changes in steroid hormones in the sera and peritoneal fluid of patients with endometriosis. Fertil Steril. 2004;81(5):1235-1239.

68. Rambulangi S. The balance of matrix metalloproteinase-2 (Mmp-2) and tissue inhibitor of matrix metalloproteinase-2 (Timp-2) on severe endometriosis. J Gynecol Obstet. 2015;3(6):111-114.

69. Szamatowicz J, Laudański P, Tomaszewska I. Matrix metalloproteinase- 9 and tissue inhibitor of matrix metalloproteinase-1: a possible role in the pathogenesis of endometriosis. Hum Reprod. 2002;17(2):284-288.

70. Malvezzi H, Aguiar VG, Paz CC, Tanus-Santos JE, Penna IA, Navarro PA. Increased circulating MMP-2 levels in infertile patients with moderate and severe pelvic endometriosis. Reprod Sci. 2013;20(5): 557-562.

71. De Sanctis P, Elmakky A, Farina A, et al. Matrix metalloproteinase-3 mRNA: a promising peripheral blood marker for diagnosis of endometriosis. Gynecol Obstet Invest. 2011;71(2):118-123.

72. Canis M, Bourdel N, Houlle C, Gremeau AS, Botchorishvili R, Matsuzaki S. Endometriosis may not be a chronic disease: an alternative theory offering more optimistic prospects for our patients. Fertil Steril. 2016;105(1):32-34.

73. Leyendecker G, Wildt L. A new concept of endometriosis and adenomyosis: tissue injury and repair (TIAR). Horm Mol Biol Clin Investig 2011;5(2):125-142.

74. Gill SE, Parks WC. Metalloproteinases and their inhibitors: regulators of wound healing. 2008;40:1334-1347.

75. Caley MP, Martins VL, O'Toole EA. Metalloproteinases and wound healing. Adv Wound Care. 2015;4(4):225-234.

76. Rahmioglu N, Montgomery GW, Zondervan KT. Genetics of endometriosis. Womens Health (Lond). 2015;11(5):577-586.

77. Trovó de Marqui AB. Genetic polymorphisms and endometriosis: contribution of genes that regulate vascular function and tissue remodeling. Rev Assoc Med Bras. 2012;58(5):620-632.

78. Shan K, Ying W, Jian-Hui Z, Wei G, Na W, Yan L. The function of the SNP in the MMP1 and MMP3 promoter in susceptibility to endometriosis in China. Mol Hum Reprod. 2005;11(6):423-427.

79. Saare M, Lamp M, Kaart T, et al. Polymorphisms in MMP-2 and MMP-9 promoter regions are associated with endometriosis. Fertil Steril. 2010;94(4):1560-1563.

80. Han YJ, Kim HN, Yoon JK, et al. Haplotype analysis of the matrix metalloproteinase-9 gene associated with advanced-stage endometriosis. Fertil Steril. 2009;91(6):2324-2330.

81. Cho YJ, Kim NH, Jeong KA, et al. Association between MMP-2 and TIMP-2 gene polymorphisms and advanced-stage endometriosis in Korean women. Am J Reprod Immunol. 2013;69(1):73-84.

82. Kang S, Zhao XW, Wang N, Chen SC, Zhou RM, Li Y. Association of polymorphisms of the MMP-2 and TIMP-2 genes with the risk of endometriosis in North Chinese women. Fertil Steril. 2008;90(5):2023-2029.

83. Adachi S, Tajima A, Quan J, et al. Meta-analysis of genome-wide association scans for genetic susceptibility to endometriosis in Japanese population. J Hum Genet. 2010;55(12):816-821.
84. Hata Y, Nakaoka H, Yoshihara K, et al. A nonsynonymous variant of IL1A is associated with endometriosis in Japanese population. J Hum Genet. 2013;58(8):517-520.

85. Sapkota Y, Low SK, Attia J, et al. Association between endometriosis and the interleukin 1A (IL1A) locus. Hum Reprod. 2015;30(1):239-248.

86. Singer CF, Marbaix E, Kokorine I, et al. Paracrine stimulation of interstitial collagenase (MMP-1) in the human endometrium by interleukin 1 alpha and its dual block by ovarian steroids. Proc Natl Acad Sci U S A. 1997;94(19):10341-10345.

87. Pretto CM, Gaide Chevronnay HP, Cornet PB, et al. Production of interleukin- $1 \alpha$ by human endometrial stromal cells is triggered during menses and dysfunctional bleeding and is induced in culture by epithelial interleukin-1alpha released upon ovarian steroids withdrawal. $J$ Clin Endocrinol Metab. 2008;93(10):4126-4134.

88. Wolber EM, Kressin P, Meyhöfer-Malik A, Diedrich K, Malik E. Differential induction of matrix metalloproteinase 1 and 2 in ectopic endometrium. Reprod Biomed Online. 2003;6(2):238-243.

89. Nap AW, Dunselman GA, de Goeij AF, Evers JL, Groothuis PG Inhibiting MMP activity prevents the development of endometriosis in the chicken chorioallantoic membrane model. Hum Reprod. 2004; 19(10):2180-2187.

90. Juhasz-Böss I, Hofele A, Lattrich C, Buchholz S, Ortmann O, Malik E. Matrix metalloproteinase messenger RNA expression in human endometriosis grafts cultured on a chicken chorioallantoic membrane. Fertil Steril. 2010;94(1):40-45.

91. Grummer R. Animal models in endometriosis research. Hum Reprod Update. 2006;12(5):641-649.

92. Bruner KL, Matrisian LM, Rodgers WH, Gorstein F, Osteen KG. Suppression of matrix metalloproteinases inhibits establishment of ectopic lesions by human endometrium in nude mice. J Clin Invest. 1997;99(12):2851-2857.

93. Jana S, Rudra DS, Paul S, Swarnakar S. Curcumin delays endometriosis development by inhibiting MMP-2 activity. Indian J Biochem Biophys 2012;49(5):342-348.

94. Mönckedieck V, Sannecke C, Husen B, et al. Progestins inhibit expression of MMPs and of angiogenic factors in human ectopic endometrial lesions in a mouse model. Mol Hum Reprod. 2009;15(10):633-643.

95. Khoufache K, Bondza PK, Harir N, et al. Soluble human IL-1 receptor type 2 inhibits ectopic endometrial tissue implantation and growth: identification of a novel potential target for endometriosis treatment. Am J Pathol. 2012;181(4):1197-1205.

96. Khoufache K, Bazin S, Girard K, et al. Macrophage migration inhibitory factor Antagonist blocks the development of endometriosis in vivo. PLoS One. 2012;7(5):e37264.

97. Zhou WD, Yang HM, Wang Q, et al. SB203580, a p38 mitogen-activated protein kinase inhibitor, suppresses the development of endometriosis by down-regulating proinflammatory cytokines and proteolytic factors in a mouse model. Hum Reprod. 2010;25(12):3110-3116.

98. Lu Z, Zhang W, Jiang S, Zou J, Li Y. Effect of oxygen tensions on the proliferation and angiogenesis of endometriosis heterograft in severe combined immunodeficiency mice. Fertil Steril. 2014;101(2): $568-576$.

99. Bayoglu Tekin Y, Guven S, Kirbas A, Kalkan Y, Tumkaya L, Guvendag Guven ES. Is resveratrol a potential substitute for leuprolide acetate in experimental endometriosis? Eur J Obstet Gynecol Reprod Biol. 2015;184:1-6.

100. Sokalska A, Cress A, Bruner-Tran KL, et al. Simvastatin decreases invasiveness of human endometrial stromal cells. Biol Reprod. 2012;87(1):2, 1-6.

101. Uzunlar O, Ozyer S, Engin-Ustun Y, et al. Effects of repeated propranolol administration in a rat model of surgically induced endometriosis. Eur J Obstet Gynecol Reprod Biol. 2014;182:167-171.

102. Machado DE, Berardo PT, Palmero CY, Nasciutti LE. Higher expression of vascular endothelial growth factor (VEGF) and its receptor VEGFR-2 (Flk-1) and metalloproteinase-9 (MMP-9) in a rat model of peritoneal endometriosis is similar to cancer diseases. J Exp Clin Cancer Res. 2010;29(1):4. 
103. Quattrone F, Sanchez AM, Pannese M, et al. The targeted delivery of interleukin 4 inhibits development of endometriotic lesions in a mouse model. 2015;22(9):1143-1152.

104. Yilmaz B, Sucak A, Kilic S, et al. Metformin regresses endometriotic implants in rats by improving implant levels of superoxide dismutase, vascular endothelial growth factor, tissue inhibitor of metalloproteinase-2, and matrix metalloproteinase-9. Am J Obstet Gynecol. 2010;202(4):368.e1-e8.

105. Wu R, Zhou W, Chen S, et al. Lipoxin A4 suppresses the development of endometriosis in an ALX receptor-dependent manner via the $\mathrm{p} 38$ MAPK pathway. Br J Pharmacol. 2014;171(21):4927-4940.

106. Kumar R, Clerc AC, Gori I, et al. Lipoxin A4 prevents the progression of de novo and established endometriosis in a mouse model by attenuating prostaglandin E2 production and estrogen signaling. PLoS One. 2014;9(2):e89742.

107. Yildirim B, Guler T, Akbulut M, Oztekin O, Sariiz G. 1-alpha,25dihydroxyvitamin D3 regresses endometriotic implants in rats by inhibiting neovascularization and altering regulation of matrix metalloproteinase. Postgrad Med. 2014;126(1):104-110.

108. Paul S, Bhattacharya P, Das Mahapatra P, Swarnakar S. Melatonin protects against endometriosis via regulation of matrix metalloproteinase-3 and an apoptotic pathway. J Pineal Res. 2010;49(2):156-168.

109. Palmer SS, Altan M, Denis D, et al. Bentamapimod (JNK inhibitor AS602801) induces regression of endometriotic lesions in animal models. Reprod Sci. 2016;23(1):11-23.

110. Coudyzer P, Lemoine P, Jordan BF, et al. Hypoxia is not required for human endometrial breakdown or repair in a xenograft model of menstruation. FASEB J. 2013;27(9):3711-3719.

111. Coudyzer P, Lemoine P, Po C, et al. Induction of post-menstrual regeneration by ovarian steroid withdrawal in the functionalis of xenografted human endometrium. Hum Reprod. 2015;30(5):1156-1168.
112. Platteeuw L, D'Hooghe T. Novel agents for the medical treatment of endometriosis. Curr Opin Obstet Gynecol. 2014;26(4): 243-252.

113. Swarnakar S, Paul S. Curcumin arrests endometriosis by downregulation of matrix metalloproteinase-9 activity. Indian J Biochem Biophys. 2009;46(1):59-65.

114. Kats R, Metz CN, Akoum A. Macrophage migration inhibitory factor is markedly expressed in active and early-stage endometriotic lesions. J Clin Endocrinol Metab. 2002;87(2):883-889.

115. Takemura Y, Osuga Y, Yoshino O, et al. Metformin suppresses interleukin (IL)-1beta-induced IL-8 production, aromatase activation, and proliferation of endometriotic stromal cells. J Clin Endocrinol Metab. 2007;92(8):3213-3218.

116. Gibran L, Maranhao RC, Abrao MS, Baracat EC, Podgaec S. Could statins constitute a novel treatment for endometriosis? Systematic review of the literature. Eur J Obstet Gynecol Reprod Biol. 2014;179:153-158.

117. Bruner-Tran KL, Osteen KG, Duleba AJ. Simvastatin protects against the development of endometriosis in a nude mouse model. J Clin Endocrinol Metab. 2009;94(7):2489-2494.

118. Yilmaz B, Ozat M, Kilic S, et al. Atorvastatin causes regression of endometriotic implants in a rat model. Reprod Biomed Online. 2010;20:291-297.

119. Zhang T, Fang X, Gang J. Endostatin gene therapy for endometriosis in rats. J Int Med Res. 2012;40(5):1840-1849.

120. Mohan V, Talmi-Frank D, Arkadash V, Papo N, Sagi I. Matrix metalloproteinase protein inhibitors: highlighting a new beginning for metalloproteinases in medicine. Met Med. 2016;3:31-47.

121. Gene Expression Omnibus. Available from: https://www.ncbi.nlm. nih.gov/geo/query/acc.cgi?acc=GSE51981. Accessed July 25, 2016.
Metalloproteinases In Medicine

\section{Publish your work in this journal}

Metalloproteinases In Medicine is an international, peer reviewed, open access journal that aims to provide a platform for the discussion and dissemination of knowledge about the role that metalloproteinases - such as matrix metalloproteinases (MMP), ADAMs, ADAMTSs, and astacins, as well as their inhibitors - play in diseases.

\section{Dovepress}

The manuscript management system is completely online and includes a very quick and fair peer review system, which is all easy to use. Visit http://www.dovepress.com/testimonials.php to read real quotes from published authors. 